\title{
Investigation on Mechanical Properties of Hybrid Polymer Composite Reinforced by Rice Husks and Date Palm Fibers as a Construction Material
}

\author{
Sihama Issa Salih*, Aseel Subhi Jasim ${ }^{* * 1}$ and Ammar Mousa Hasan* \\ *Department of Materials Engineering, University of Technology, Baghdad-Iraq. \\ ** Department of Human Resources, Head Quarter, Al-Nahrain University, Baghdad-Iraq. \\ ${ }^{1}$ E-mail: aseelmap79@yahoo.com.
}

\begin{abstract}
In this study the boards were fabricated from unsaturated polyester resin reinforced by rice husk and date palm fibers, with the total volume fraction of reinforcement materials was $(30 \%)$ using different value of filler loading including the ratios $(0 / 30,5 / 25,10 / 2015 / 15,20 / 10,25 / 5$ and 30/0) for volume fraction of date palm fibers/ rice husk, two groups of the hybrid composite were prepared depending on the length of palm fibers, the first group have palm fibers its length 2-3 mm and second group have short fibers its length less than $1 \mathrm{~mm}$. The fabricated boards were evaluated for the mechanical properties (tension, compression, flexural, and impact tests) for all the prepared samples were studied. The results from this work show that all of these properties increase with increased the volume fraction of palm fiber at the expense of the proportion of rice husks in hybrid composite. Decreasing the length of fibers from $(2-3 \mathrm{~mm})$ to micro-sized length (less than $1 \mathrm{~mm}$ ) increased the mechanical properties of flexural strength, maximum shear stress, flexural modulus, and fracture toughness of the prepare composites. Moreover the mechanical properties of the polyester composite reinforced with date palm fibers gave better mechanical properties than the polyester composite reinforced with rice husk.
\end{abstract}

Keywords: hybrid composite, Polymer Composites; Rice Husk; date palm fibers and mechanical properties.

\section{Introduction}

The development of polymer composites from renewable raw materials has been increased considerably during the last few years [1-2]. The organic filler have becoming strong competitors to this traditional inorganic filler due to their low densities, very low cost, non-abrasiveness [2-3]. The use of natural fibers ,derived from a number of renewable resources, as reinforcing materials in both thermoplastic and thermoset matrix composites provides positive environmental benefits with respect to ultimate disposability and best utilization of raw materials [3-4].

Particularly, a number of studies have shown that synthetic fibers reinforced polymeric materials possess a best mechanical efficiency but the increase in cost and its effect on the environment, due to this kind of fibers have forced scientists and engineers to synthesize new materials of low specific weight, low cost and renewable resources, Reduced wear of tooling, good thermal and acoustic insulating properties, and environmentally friendly, like vegetable fibers [3-5].

Currently, natural fibers as reinforcements in technical applications are mainly used in the building and construction industry, automobile, electric devices, and packaging industries in parts where a high load carrying capacity is not required [6].

Natural fiber mechanical characteristics are influenced by parameters such as the crystalstructure, the degree of crystallinity, the degree of polymerization, the porosity content, the size of the lumen (a center void), and the chemical composition [6-7]. Biofibers (lignocelluloses) consist mainly of three components. These are cellulose, hemicelluloses and lignin. It has been reported that the mechanical properties of natural fibers is related to its cellulose type and content [7]. Hemicelluloses and lignin work as cementing material between cellulose micro fibrils [8]. The composition of natural fibers, and thus the fiber properties, is affected by several parameters such as soil quality, weathering, 
level of plant maturity and quality of the retting process [9].

One of the major problems associated with the use of natural fibers in composites is their high moisture sensitivity leading to severe reduction of mechanical properties and delaminating. The reduction in mechanical properties may be due to poor interfacial bonding between resin matrices and fibers. It is therefore necessary to modify the fiber surface to render it more hydrophobic and also more compatible with resin matrices [10].

In the previous investigations the reinforcing capability of palm tree fibers in thermoplastic or thermoset polymer matrices was demonstrated [11]. Strong interactions gave rise to enhanced mechanical and thermal characteristics. The size of the fibers was also found to have an effect on the properties [11-12].

A. Djoudi et al. et al studied the effect of addition date palm fibers with construction material composed of plaster, sand, crushed gravel on some mechanical and physical properties of a new composite. The results showed that the incorporated vegetable fibers changed the mechanical behavior of the material and increased considerably its ductility, improving its cracking threshold [13]. The pre-deformation for petiole date palm fiber improves the mechanical and physical properties of composite [14].

Many studies dealing with polymer-rice husk composition [15-17]. The mechanical properties and the percentage of water absorption of the rice husk filler unsaturated polyester composite had been studied by K. Hardinnawirda and I. SitiRabiatull Aisha, results show that the tensile strength of the $\mathrm{RH}$ filled unsaturated polyester composite found to be decrease as the filler loading increase. However, as it increases to $25 \mathrm{wt} \%$, the strength shows moderately increase. As for the young modulus, it shows remarkable increase for $15 \mathrm{wt} \%$ of $\mathrm{RH}$ and decreasing as the $\mathrm{RH}$ continually increase up to $25 \mathrm{wt} \%$ [15]. Study the effect of natural and calcined temperature of rice husk ash on the mechanical and thermal properties for the prepared hybrid composite. The results show that the mechanical and thermal properties increased with increasing the calcined temperature and the best calcining temperature of rice husk ash is $1300{ }^{\circ} \mathrm{C}$ [17].

The objective of the this work used the date palm fibers and rice husks to prepare hybrid composite with the total volume fraction for reinforcement materials was (30\%) and study the mechanical properties of a different ratios of rice husk proportional to the content ratio of palm fibers in hybrid composite.

\section{Selection of Materials}

In this investigation unsaturated polyester resin was used as matrix material, supplied by (SIR) Saudi company. It is one type of polymers hardening thermally, viscous liquid, and characteristic as transparent liquid at room temperature converted to a solid state by adding suitable hardener (which is a Methyl Ethyl Keton peroxide supplied by the company itself) to form a strong permanent band converted to a solid state, the weight ratio between hardener and resin was $2 \mathrm{gm}$ of hardener per $100 \mathrm{gm}$ of the resin. Rice husk which is obtain from Al-Najaf rice farm, as the filler material there is series of operations had been carried on the rice husks, at first the rice husk used were taken from rice mills. The second filler material is date palm fibers were collected locally from the date trees obtained mainly from Baghdad former in middle of Iraq. The fibers were taken from petiole of date.

\section{Preparation of rice-husk and date palm fibers}

The rice-husk and date palm fibers were initially underwent a treatment process in order to strengthen the sample structure. The treatment was also done to obtain the cleanest appearance to the rice husk and date palm fibers. Initially, the rice-husk and date palm fibers were washed thoroughly with detergent powder in order to remove dust and mud. After that, these fibers were soaked in hot distilled water for $2 \mathrm{~h}$, dried for $72 \mathrm{~h}$ in air at room temperature. Then, soaked palm fiber, and also rice husks in apple cider vinegar at room temperature for 48 hours, and return it washed in distilled water and then dried in the same previous conditions, afterward the dry fillers were immersing in $95 \%$ mixture of Natrium Hydroxide $(\mathrm{NaOH})$ and $5 \%$ of water. This immersion process took time up to 
24 hours. Next, the immersed rice husk and date palm fibers were washed with distilled water several times and then exposed to the heat of the sun for about 24 hours. In order to ensure the rice husk and date palm fiber was totally clean and strong, the rice husk Fig.(1 a) and date palm fibers were dried in the oven with $70{ }^{\circ} \mathrm{C}$ for about 12 hours. Finally, the date palm fibers were threaded into pieces and stretched to a specified length and diameter; these fibers Fig. $(1 \mathrm{~b})$ were used in two forms as shown below:

- Date palm Fibers were chopped into (2-3) $\mathrm{mm}$ length these fibers were used as short fibers Fig.(1c).

- Some of the cleaned date palm fibers were ground in the rotary cutting mill type (bran bender Duisburg 880804) to get very short fibers as a powder with the particle size less than $1 \mathrm{~mm}$ Fig. $(1 \mathrm{~d})$.

In this paper, hybrid polymer composite was prepared, which was reinforced by rice husk and palm fiber, with a total volume ratio of reinforcement materials were $(30 \%)$. Table (1) shows the proportions of each of the rice husk and palm fibers in the hybrid composite.

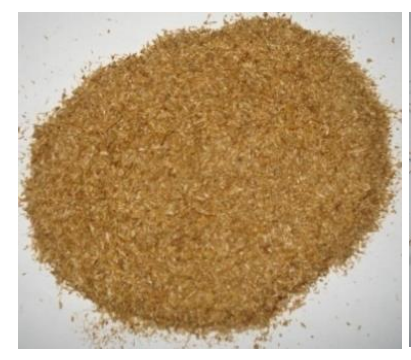

(a)

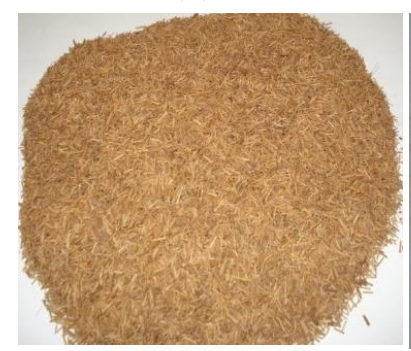

(c)

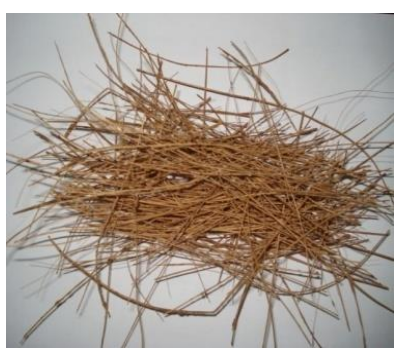

(b)

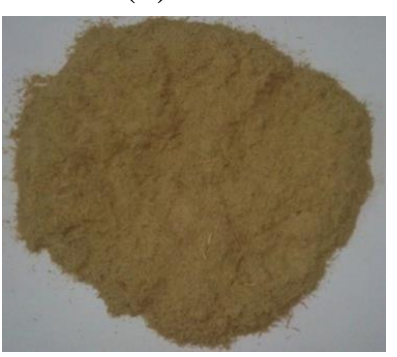

(d)

\begin{tabular}{|c|c||c|c||}
\hline composition & $\begin{array}{c}\text { Vol.\% of } \\
\text { polyester } \\
\text { resin }\end{array}$ & $\begin{array}{c}\text { Vol.\% } \\
\text { of rice } \\
\text { husk }\end{array}$ & $\begin{array}{c}\text { Vol.\% of } \\
\text { date palm } \\
\text { fibers }\end{array}$ \\
\hline \hline 1 & 70 & 30 & 0 \\
\hline 2 & 70 & 25 & 5 \\
\hline \hline 3 & 70 & 20 & 10 \\
\hline \hline 4 & 70 & 15 & 15 \\
\hline \hline 5 & 70 & 10 & 20 \\
\hline \hline 6 & 70 & 5 & 25 \\
\hline 7 & 70 & 0 & 30 \\
\hline
\end{tabular}

Fig. (1) (a) rice husk particles, (b) data palm fibers, (c) short fibers (d) micro-size data palm fibers.

\section{Composite Preparation}

Hand lay-out technique was used to prepare the composite specimens; a mould of size $(250 \times 250 \times 5) \mathrm{mm}^{3}$ was made from plate glass. Sheet of polyvinyl alcohol substance was fixed on the inner mould faces before casting to facilitate the releasing of casting polymer and having smooth faces. Palm fibers with length (2-3 $\mathrm{mm})$ and nearly with fixed diameter equal to $1 \mathrm{~mm}$ after proper purification surface modification and drying, divides into two parts as mentioned earlier. Then each part were thoroughly mixed with rice husk and polyester resin by different loading in terms of volume fraction as mentioned in Table (1), then the mixture was poured into the mould and allowed to cure for $72 \mathrm{~h}$ at room temperature $(23 \pm 2) \quad 0^{\circ} \mathrm{C}$. After solidification, all the specimens (sheets) released from the mould then post cured in an electrical oven at $55^{\circ} \mathrm{C}$ for $2 \mathrm{~h}$. Composite sheets of size (240x $240 \times 5) \mathrm{mm}^{3}$ Fig.(2 a) cut off and machined according to standard specifications to produce samples conforming for mechanical properties test.

\section{Mechanical Test}

Prepared samples for the tensile test were cut according to ASTM D638 [18] Fig.(2 b). The machine used for testing is micro computer controlled electronic universal testing machine (model WDW $200 \mathrm{E}$ ) made in china. The test was conducted at constant cross head speed of the order of $(5 \mathrm{~mm} / \mathrm{min})$ at ambient temperature. Tensile stress was applied till the failure of the sample and stressstrain curve was obtained. The result reported 
for each sample represent the average of three samples it was tested.

Bending behavior of the prepared sample was tested using a three point test instrument, (model WDW $200 \mathrm{E}$ ) according to ASTM D790-78 [18-19] Fig.(2 c), at room temperature with velocity $(5 \mathrm{~mm} / \mathrm{min})$ until the failure of the specimen occurs. The result reported for each sample represent the average of three samples it was tested, flexural strength ( $\sigma$ bend), maximum shear stress (i) and flexural modulus are valued from the relationships (1-3) respectively.

Flexural strength for three-point bend test $=\sigma$ bend $=\frac{3 \mathrm{FL}}{2 \mathrm{wh}^{2}}$

Where $\mathrm{F}$ is the fracture load, $\mathrm{L}$ is the distance between the two outer supporting points, $w$ is the width of the specimen, and $h$ is the thickness of the specimen.

Maximum shear stress $\tilde{\mathrm{i}}=\frac{3 \mathrm{~F}}{4 \mathrm{wh}}$
Flexural modulus $=\mathrm{Ef}=\frac{\mathrm{FL}^{3}}{4 \partial \mathrm{wh}^{3}}=\frac{\mathrm{mL}^{3}}{4 \mathrm{wh}^{2}} \ldots \ldots \ldots \ldots \ldots \ldots$

Where $\partial$ is the deflection of the beam when a force $\mathrm{F}$ is applied, $\mathrm{m}$ is the slope of the load (F) /deflection curve.

The compression test is performed according to (ASTM D695) [18] at room temperature $\left(23 \pm 2{ }^{\circ} \mathrm{C}\right)$ by used universal testing machine (model WDW $200 \mathrm{E}$ ) made in china, at across head (strain rate) of $(5 \mathrm{~mm} / \mathrm{min})$ and load was applied until break the specimen occur. The result reported for each sample represent the average of five samples it was tested.

Impact test is performed at room temperature according to ASTM ISO 179 [19] at room temperature $\left(23 \pm 2{ }^{\circ} \mathrm{C}\right)$ by using Izod Impact test machine type is (XJU series pendulum Izod/Charpy impact testing machine). For an Izod test: the specimen clamped at one end and held vertically cantilevered beam and it has broken at impact energy of $(5.5 \mathrm{~J})$ of pendulum and impact velocity $(3.5 \mathrm{~m} / \mathrm{s})$. The result reported for each sample represent the average of five samples it was tested.

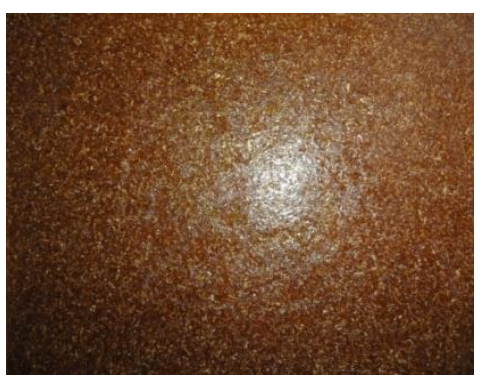

(a)

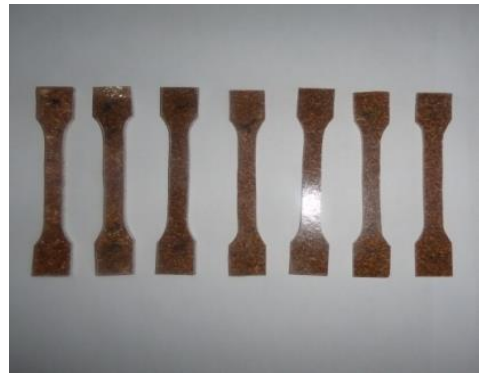

(b)

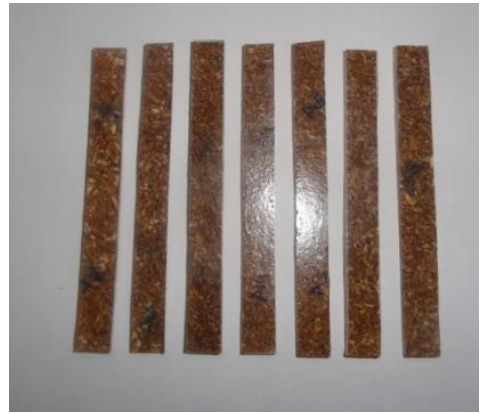

(c)

Fig.(2) (a) Composite sheet as prepared, (b) the specimens of the tensile test and (c) the specimens of bending test.

\section{Results and Discussions}

Fig. (3) shows the stress-strain curves of first group (with short fibers) of hybrid polymer composite, which contains on polyester with constant volume fraction $(70 \%)$ in all samples, whereas the total volume fraction for reinforcement materials $(30 \%)$, the volume fraction of the palm fibers in hybrid polymer composite, was increasing relative to the volume fraction of rice husk in hybrid polymer composite from the total volume fraction $(30 \%)$. As shown from these curves all the prepared samples show plastic behavior with tensile load, and the behavior changes from weak and soft for polymer composite when reinforced with $30 \%$ of rice husk only to strong with increasing the volume fraction of palm fibers(with short fibers) in hybrid polymer composite. 


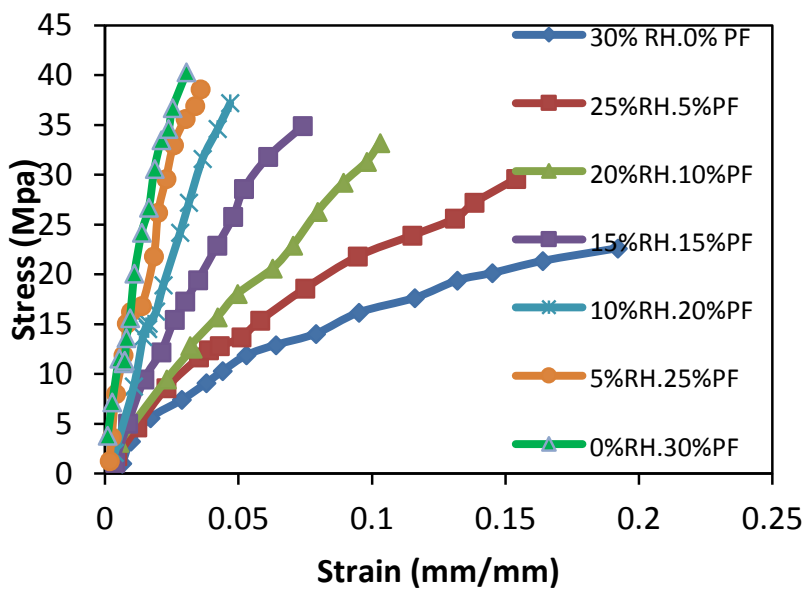

Fig. (3) The stress-strain curves of the first group samples of hybrid polymer composite as function of palm fibers (with short fibers) in hybrid composite.

while Fig.(4) shows the stress-strain curves of second group of composites which consists also from polyester with constant volume fraction $(70 \%)$ in all samples, with the increasing of the volume fraction of palm fibers (after the grinding) in relative to volume fraction of rice husk in reinforcement materials (with the total volume fraction (30\%)). As shown from those curves, all the prepared composites show plastic behavior with tensile stress and the behavior changes from weak and soft for polymer composite when reinforced with $30 \%$ of rice husk only to strong and hard with increasing the volume fraction of grinding palm fibers in hybrid polymer composite. As well as the significant decrease in the elongation at break of the second group composites with the addition grinding palm fibers in hybrid composite. It was found that the elongation of the samples which is free from palm fibers is $0.192 \%$ while elongation of the samples which owns $30 \%$ of the grinding palm fibers decreased to $0.0203 \%$ and that will be explained later through charts.

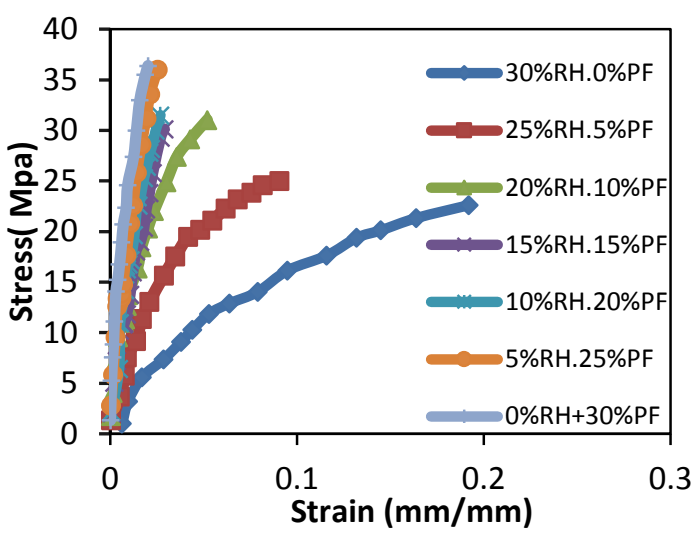

Fig. (4) The stress-strain curves of the second group samples of hybrid polymer composite as function of (grinding) palm fibers in hybrid composite.

Figs. (5) and (6) illustrate the effect of palm fibers content on the fracture strength and young modulus values respectively of the prepared composites before and after the grinding palm fibers. These figures indicate that the addition of palm fibers to composites increases the fracture strength and young modulus values of these hybrid composites, as well as was observed from Figs. (5) and (6) that the fracture strength and young modulus values of the hybrid composite, it was increased with increasing the palm fibers ratio in the total volume fraction of the fillers in the composite as compared to ratio of rice husk in the fillers. And that is related to the structural nature of rice husk which contains gabs inside, these gabs reduce the bonding force between the rice husk and the matrix, while in the case of addition of palm fibers relative to volume fraction of rice husk in reinforcement materials, the process of penetration of the matrix much better so the bonding force at the interface will increase which increase the fracture strength and Young's modulus [10].

And also it can be noticed from Figs. (5) and (6) that the fracture strength and Young's modulus values of the first group composite are slightly higher than that values for the second group of hybrid composite having the same ratios of palm fiber, and that is due to the ability of the palm fibers have short lengths to withstand the loads as compared with the grinded the palm fibers, this result is similar to those reported in previous research [11and12].

While the elongation at break (\% ductility) for both groups of prepared composites it was 
decrease with increasing palm fibers content in the composites as shown from Fig.(7). And also it can notice from the figure that the $\%$ ductility values for all samples of the first group composites are high as compared with their counterpart of the second group samples of composites. However decrease in fiber length can be a useful factor for enhancing the interface contact, this effect reduce the micropore media. So the short date palm fibers cause to increased density that causes decrease in the ductility [11 and 12].

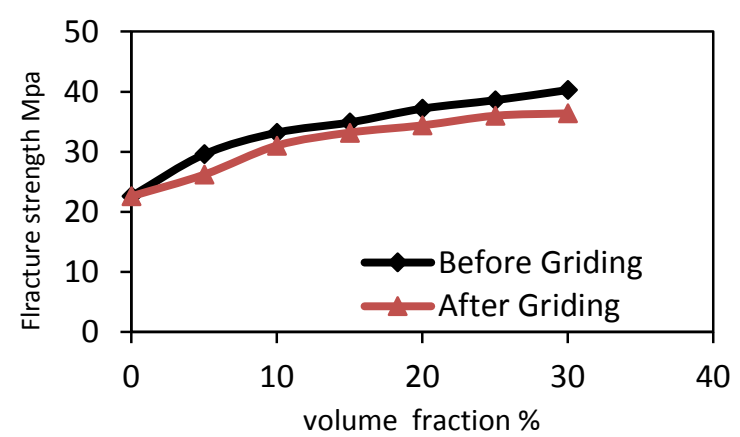

Fig. (5) Tensile strength at break of hybrid polymer composite as function of palm fibers in composite.

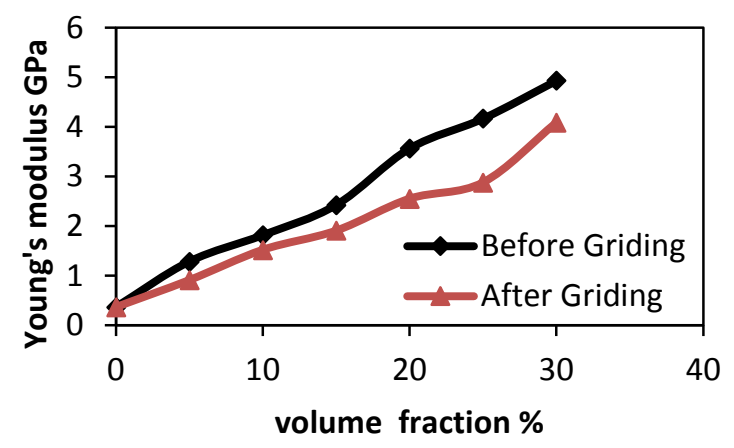

Fig. (6) Young modulus of hybrid polymer composite as function of palm fibers in composite.

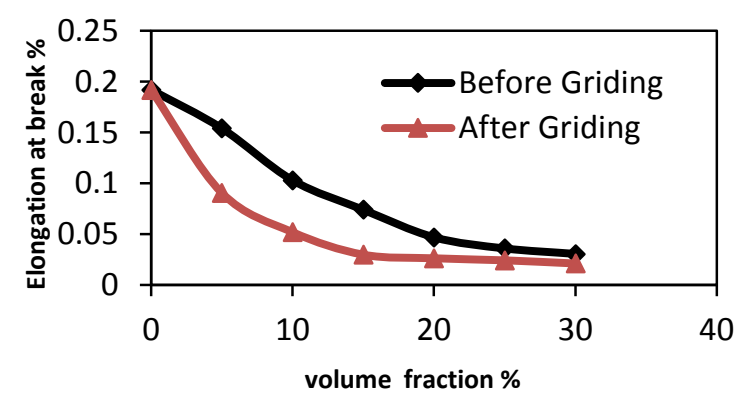

Fig. (7) Elongation at break of hybrid polymer composite as function of palm fibers in composite.

\section{Compression test}

From the results of stress-strain curves for compression test of the two groups of prepared composite sit is found that the compressive strength as shown in Fig.(8) increases with the increase of the palm fibers ratio in the prepared samples for the two groups of composites respectively. As previously mentioned, that the palm fibers were increasing relative to the volume fraction of rice husk in hybrid polymer composite from the total volume fraction of reinforcement materials $(30 \%)$. So the polyester which has the higher ratio of rice husks owns low values of compressive strength, and this corresponds with the results of the researchers $K$. Hardinnawirda and I. SitiRabiatull [15]. And also it was found from figure that the values of compressive strength was higher for all samples which was reinforced by palm fibers Length of 2-3 $\mathrm{mm}$ of the first group composites as compared with their counterparts of the samples of the second group composites reinforced by the grinded palm fibers to the length less than $1 \mathrm{~mm}$ (micro-sized).

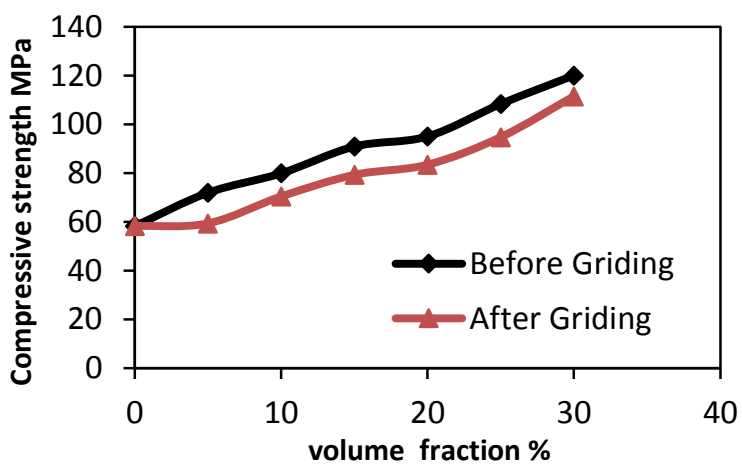

Fig. (8) Compressive Strength of hybrid polymer composite as function of palm fibers in composite.

\section{Flexural Test}

The flexural strength and maximum shear stress values for two group's composites as a function of palm fibers content are shown in Figs. (9) and (10) respectively. From these figures it is found that increase in flexural stress and maximum shear stress values with the increased palm fibers content in the prepared composites. And this related to the natural of the rice husk and the palm fibers which have higher flexible compared to the 
polyester matrix. Moreover it can be noticed that there is asymmetry in these values for two group's composites, Furthermore, grind the date palm fibers to the length less than $1 \mathrm{~mm}$ (micro-size). enhanced the flexural strength and maximum shear stress values of hybrid composite material, that contain date palm fibers have micro-sized length as compared with their counterparts of the other samples of first group composites, reinforced from palm fibers length of 2-3 $\mathrm{mm}$.

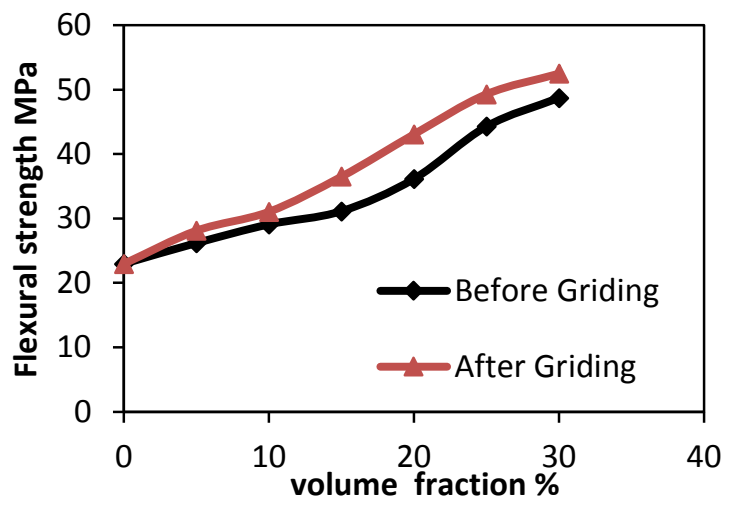

Fig. (9) Flexural Strength of hybrid polymer composite as function of palm fibers in composite.

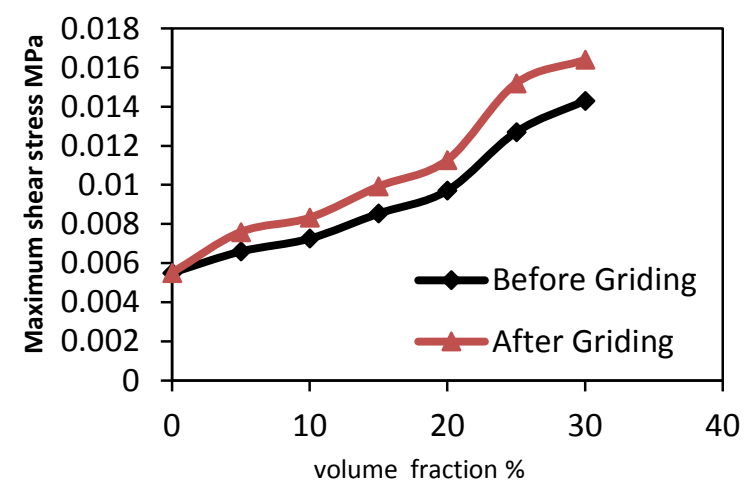

Fig. (10) Maximum Shear Stress of hybrid polymer composite as function of palm fibers in composite.

Fig.(11) shows the effect of palm fibers ratio on the flexural modulus of both groups of composites, which reveals that the addition of palm fibers in the composites increases the flexural modulus values of both prepared composites groups, but the rate of increment in flexural modulus values of the second group specimens, which reinforced by the grinded palm fibers to the length less than $1 \mathrm{~mm}$ (micro-sized), is larger than the flexural modulus values of the first group samples at the same ratio of palm fibers. And this related to the structural nature of palm fibers before and after grinds the palm fibers.

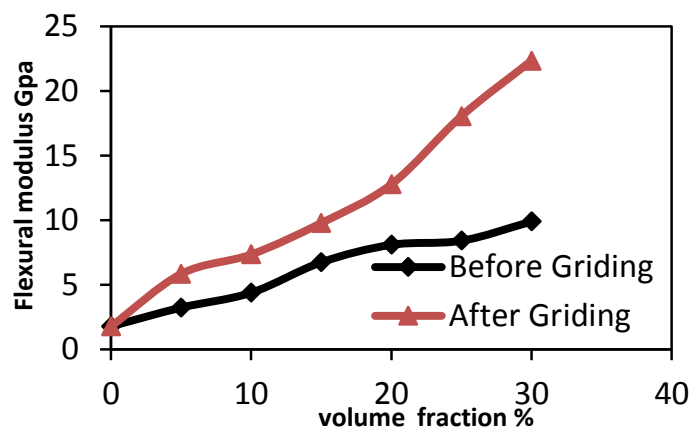

Fig. (11) Flexural modulus of hybrid polymer composite as function of palm fibers in composite.

\section{Impact Properties}

Figs. (12) and (13) show the effect of palm fibers ratio relative to volume fraction of rice husk in reinforcement materials on the impact strength and fracture toughness of both groups of composites. The impact strength and fracture toughness increase with addition of palm fibers to the rice husk composites. As well as it was observed from Fig.(12), that the values of impact strength was higher for all samples of the first group composites, which was reinforced by palm fibers Length of 2-3 $\mathrm{mm}$, as compared with their counterparts of the samples of second group composites, which was reinforced by the grinded palm fibers to the length less than $1 \mathrm{~mm}$, whereas values of the fracture toughness Fig.(13) for specimens second group composites higher than the values of counterparts of samples of the first group composites. And that it is related to the structural nature of palm fibers before and after grinds the palm fibers, and the bonding nature between the interfaces of the constituents of the hybrid composite [10].

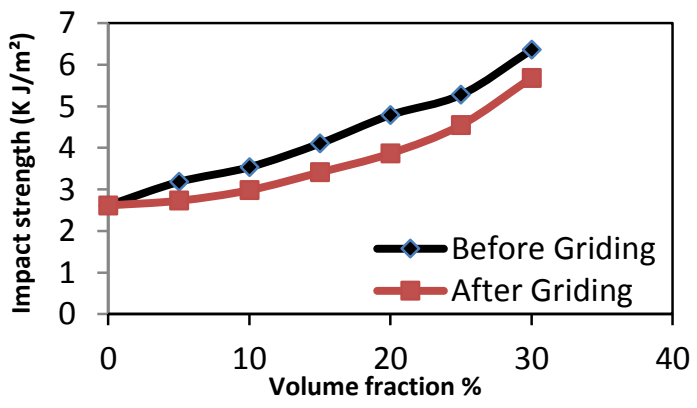

Fig. (12) Impact Strength of hybrid polymer composite as function of palm fibers in composite. 


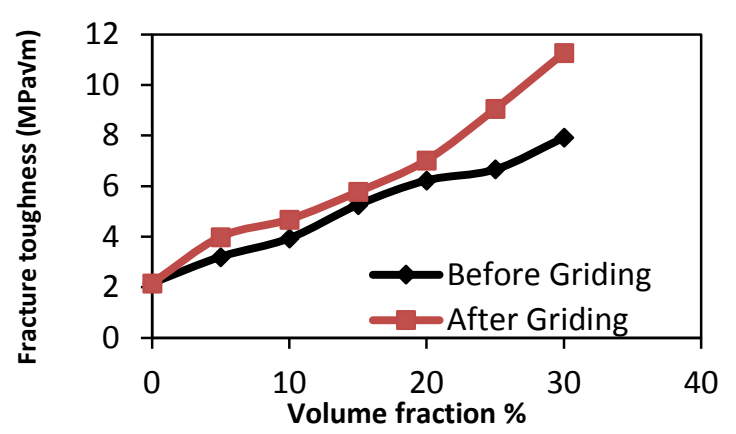

Fig. (13) Fracture Strength of hybrid polymer composite as function of palm fibers in composite.

\section{Conclusions}

In this research was chosen the hybrid composite materials. Has the total volume fraction of the reinforcement materials is $30 \%$, consist of date palm fibers and rice husk. Some of the mechanical properties, of the hybrid composites, were investigated under the effect of nature of reinforcement materials in the composite, with the different of palm fibers lengths. Was concluded the following items:-

The fracture strength, young modulus, compressive strength, flexural strength, maximum shear stress, flexural modulus, impact strength and fracture toughness of hybrid composites it was increased with the increasing ratio of palm fibers in the polymer composites.

Decreasing the length of fibers from (1-3mm) to micro-sized length (less than $1 \mathrm{~mm}$ ) led to increased in the mechanical properties (flexural strength, maximum shear stress, flexural modulus, and fracture toughness) of the prepare composites. The fracture toughness of the polyester composite it was increased to $98 \%$ when reinforced with micro-sized length of the palm fibers.

The mechanical properties of the polyester composite reinforced with data palm fiber are better than polyester composite reinforced by rice husk.

\section{References}

[1] Chadramohan D., Marimuthu k. "Tensile and Hardness Tests on Natural Fiber Reinforced Polymer Composite Material", International Journal of advanced engineering science and technologies, 6, 97-104, 2011.
[2] Karthikeyan A. and Balamurugan K. "Effect of alkali treatment and fiber length on impact behavior of coir fiber reinforced epoxy composites", Journal of Scientific \& Industrial Research, 71, 627-631, 2012.

[3] Siddika Salma, Mansura Fayecka, and Hasan Mahbub], "Physico-Mechanical Properties of Jute-Coir Fiber Reinforced Hybrid Polypropylene Composites", World Academy of Science, Engineering and Technology, 73, 1145-1149, 2013.

[4] Dash D., Samanta S., Gautum S.S. and murlidhar M. [2013], "Mechanical characterization of natural fiber reinforced composite material", Advanced material manufacturing and characterization. 3(1), 275-280, 2013.

[5] Abilash N. and Sivapragash M., "Environmental benefits of eco-friendly natural fiber reinforced polymeric composite materials", International Journal of application or innovation in Engineering and management (IJAIEM), ISSN 23194847,.2 (1), 53-59, 2013.

[6] U.S. Bongarde, V.D. Shinde "Review on natural fiber reinforcement polymer composites" International Journal of Engineering Science and Innovative Technology (IJESIT) 3(2), 431-436, March 2014.

[7] Bledzki, A.K. and Gassan, J., "Composites reinforced with cellulose based fibers".

[8] Baley, C., "Analysis of the flax fibers tensile behavior and analysis of the tensile stiffness increase", Composites: Part A, 33, 939-948, 2002.

[9] Mohanty, A.K., Misra, M. and Hinrichsen, G., "Biofibres, biodegradable polymers and biocomposites: an overview”, Macromol. Mater. Eng. 276/277, 1-24, (2000).

[10]Satish Pujari, A. Ramakrishna and M. Suresh Kumar, "Comparison of Jute and Banana Fiber Composites: A Review" International Journal of Current Engineering and Technology No. 2. (22), 121-126, 2014. 
[11]Bendahou A, Kaddami H, Sautereau H, Raihane M, Erchiqui F, Dufresne A Short palm tree fibers poly olefin composites: Effect of filler content and coupling agent on physical properties. Macromol Mater Eng 293, 140-148, 2008.

[12] Sbiai A, Maazouz A, Fleury E, Sautereau $\mathrm{H}$, Kaddami H Short date palm tree fibers polyepoxy composites prepared using RTM process: effect of Tempo-mediated oxidation of the fibers. Bio Resources 5,672-689, 2010.

[13]Djoudi, M.M. Khenfer, A. Bali, E.H. Kadri and G. Debicki "Performance of date palm fibers reinforced plaster concrete" International Journal of Physical Sciences, 7(21), 2845-2853, 2012.

[14]S. I. Salih "Acoustic and Mechanical Properties of Polymer Composites Reinforced by Pre-Deformed Palm Fiber" Eng. \& Tech. Journal.31(3), 484-499, 2013.

[15]K. Hardinnawirda and I. SitiRabiatull Aisha, "EFFECT OF RICE HUSKS AS FILLER IN POLYMER MATRIX COMPOSITES" Journal of Mechanical Engineering and Sciences (JMES) e-ISSN: 2231-8380; 2, 181-186, 2012.

[16]Celestine, Mbakaan; Audu, Onojah; Msughter, Gbaakpen; Dooshima, Targema "Variation of Some Physical Properties of Rice Husk Ash Refractory with Temperature" International Journal of Science and Research (IJSR), India Online ISSN: 2319-7064 2 (9), 26-29, September 2013.

[17] S. E. Salih, B. Hashim, H. M. Al-tamimi "The Mechanical and Thermal Properties of Polymer Hybrid Composite Reinforced by Rice Husk Ash at Different Conditions" Eng. \& Tech. Journal 32 (A) 9, 2119-1132, 2014.

[18]Premamoy Ghosh, "Polymer Science and Technology Plastics, Rubbers, Blends and composites", second edition, Tata $\mathrm{Mx}$ Graw-hill (2002).
[19] W. F. Smith and J.Hashemi, "Foundations of Materials Science and Engineering", Fourth Edition, McGraw-Hill, (2006).

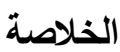

تم في هذا البحث دراسة الخواص الميكانيكية (الثد،

الانضغاطية، الانحناء، والصدمة) لمادة متراكبة هجينة

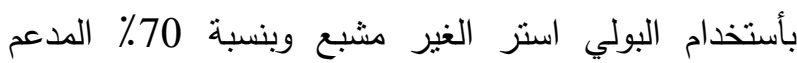

بالياف النخيل وقتور الرز بنسبة (30٪). تم تحضير

مجموعتين من المواد المتراكبة المجموعة الاولى يتراوح فيها طول الياف النخيل من(2-3) ملمتر اما المجموعة الثانية طول الياف النخيل اقل من (1) ملمنر (مطحونة) وتتاولت

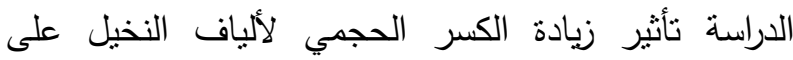
حساب الكسر الحجمي لقشور الرز على الخواص الميكانيكية وبالنسب التالية (5/30، 5/25، 10/20، 15/15، 20/10، 25/5، 30/0) وتمثل نسبة الكسر الحجمي لألياف

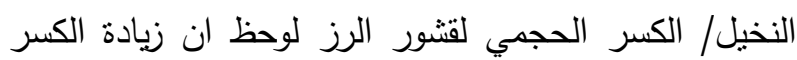
الحجمي لألياف النخيل على حساب الكسر الحجمي لقنشور الرز للمتراكب الهجيني المحضر أدى الى زيادة في كل قيم الخواص الميكانيكية وفي حالة استخدام الياف النخيل اطولها

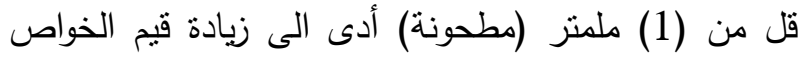
الميكانيكية المتمنلة بـ (مقاومة الاتحناء، اعلى قيمة لأجهاد

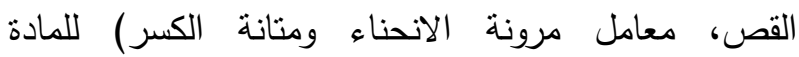
المحضرة. كما أظهرت النتائج ان قيم الخواص الميكانيكية للمادة المحضرة بأستخدام الياف النخيل وحدها كانت أفضل من القيم التي نم الحصول عليها بأستخادم مادة محضرة فقط

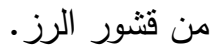

